BILIARY DISEASE

\title{
Scintigraphy versus manometry in patients with suspected biliary sphincter of Oddi dysfunction
}

\author{
A G Craig, D Peter, G T P Saccone, P Ziesing, A Wycherley, J Toouli
}

Gut 2003;52:352-357

See end of article for authors' affiliations

\section{Correspondence to:}

Professor J Toouli,

Department of General and

Digestive Surgery, Flinders

Medical Centre, Bedford

Park, South Australia

5042, Australia;

Jim.Toouli@flinders.edu.au

Accepted for publication

16 September 2002
Introduction: Sphincter of Oddi (SO) manometry is at present the "gold standard" investigation for patients with suspected biliary SO dysfunction. Non- invasive scintigraphy in cholecystectomised patients using a complex scoring system or the transit time from the hepatic hilum to the duodenum (HDTT) have been promoted as sensitive and specific alternatives.

Aim: To evaluate the scintigraphic scoring system and HDTT in patients with suspected biliary SO dysfunction undergoing SO manometry.

Methods: Cholecystectomised patients undergoing SO manometry for persistent biliary-type pain, as defined by the Rome II criteria, for which all other causes had been excluded, were prospectively studied. Scintigraphy with cholecystokinin octapeptide infusion was performed within a month prior to manometry. Scoring of the scans and measurement of HDTT was performed by independent blinded observers. Manometry of the biliary sphincter was performed per-endoscopically and defined as abnormal if basal pressure was $\geqslant 40 \mathrm{~mm} \mathrm{Hg}$.

Results: Thirty two patients were enrolled (30 females, mean age 45.1 years). Three patients were excluded from analysis because manometry from the bile duct was not technically possible. Eight patients had abnormal manometry. Scintigraphic scoring had a sensitivity of 25-38\%, a specificity of $86-89 \%$, positive predictive value (PPV) of $40-60 \%$, and a negative predictive value (NPV) of $75-79 \%$. The coefficient of variation for interobserver variation in scores was 0.72 . HDTT sensitivity was $13 \%$, specificity $95 \%$, PPV $50 \%$, and NPV $74 \%$.

Conclusions: Our findings indicate that scintigraphy using these methods of analysis correlates poorly with manometry in post cholecystectomy patients with suspected biliary SO dysfunction.
S phincter of Oddi (SO) manometry is currently the most widely accepted method of assessing SO function for patients with suspected biliary SO dysfunction. ${ }^{1}$ The most useful manometric parameter is basal pressure as sphincterotomy performed in patients with an abnormally elevated basal pressure has been found to be an effective therapy for treatment of SO dysfunction. ${ }^{23}$ However, manometry is invasive and carries a significant risk of pancreatitis that has been reported to occur in $8-17 \%$ of patients. ${ }^{45}$

Non-invasive scintigraphy has been used in the evaluation of patients with post cholecystectomy pain as a way of assessing anatomical obstruction due to retained common bile duct stones or functional obstruction due to SO dysfunction. The variables used to assess obstruction are many and include: time taken to the maximal count over the biliary tree (Tmax); time taken for $50 \%$ of tracer to accumulate over the biliary tree $\left(T_{12}\right)$; time taken for tracer to enter the duodenum; prolonged excretion of tracer from the biliary tree; and transit time of tracer from the hepatic hilum to the duodenum. Initial experience found more positive ${ }^{6-11}$ than negative ${ }^{12}$ results. However, there was variability in parameters used to assess scintigraphy, and diagnostic criteria for SO dysfunction were not uniform.

A scoring system using six scintigraphic variables was developed with the hope of improving the accuracy of scintigraphy in patients with suspected SO dysfunction. ${ }^{13}$ Using this scoring system (table 1 ), which incorporates both quantitative and qualitative measures, Sostre et al found 100\% sensitivity and specificity in 26 patients compared with manometry. This approach has not been reported by other groups.

An Italian group assessed numerous scintigraphic variables in post cholecystectomy patients and found that the hepatic hilum to duodenal transit time (HDTT) was the best predictor of delayed bile flow into the duodenum. ${ }^{14}$ This variable was

\begin{tabular}{|c|c|}
\hline Criteria & Score \\
\hline \multicolumn{2}{|l|}{ (1) Peak time } \\
\hline (a) Less than 10 minutes & 0 \\
\hline (b) 10 or more minutes & 1 \\
\hline \multicolumn{2}{|l|}{ (2) Time of biliary visualisation } \\
\hline (a) Less than 15 minutes & 0 \\
\hline (b) 15 or more minutes & 1 \\
\hline \multicolumn{2}{|l|}{ (3) Prominence of biliary tree } \\
\hline (a) Not prominent & 0 \\
\hline (b) Prominent major intrahepatic ducts & 1 \\
\hline (c) Prominent small intrahepatic ducts & 2 \\
\hline \multicolumn{2}{|l|}{ (4) Bowel visualisation } \\
\hline (a) Less than 15 minutes & 0 \\
\hline (b) $15-30$ minutes & 1 \\
\hline (c) More than 30 minutes & 2 \\
\hline \multicolumn{2}{|l|}{ (5) CBD emptying } \\
\hline (a) By more than $50 \%$ & 0 \\
\hline (b) Less than $50 \%$ & 1 \\
\hline (c) No change & 2 \\
\hline (d) Increasing activity & 3 \\
\hline \multicolumn{2}{|l|}{ (6) $\mathrm{CBD}$ to liver ratio } \\
\hline (a) $C B D^{60}<$ liver $^{60}$ & 0 \\
\hline (b) $\mathrm{CBD}^{60}>$ liver $^{60}{\text { but }<l i v e r^{15}}^{15}$ & 1 \\
\hline (c) $C B D^{60}>$ liver $^{60}$ and $=$ liver $^{15}$ & 2 \\
\hline (d) $C B D^{60}>$ liver $^{60}$ and liver ${ }^{15}$ & 3 \\
\hline
\end{tabular}

Abbreviations: CCK-OP, cholecystokinin octapeptide; CBD, common bile duct; DAT, duodenal appearance time; DIDA, diethyl iminodiacetic acid; ERCP, endoscopic retrograde cholangiopancreatography; HDTT, hepatic hilum to duodenal transit time; NPV, negative predictive value; PPV, positive predictive value; SO, sphincter of Oddi. 

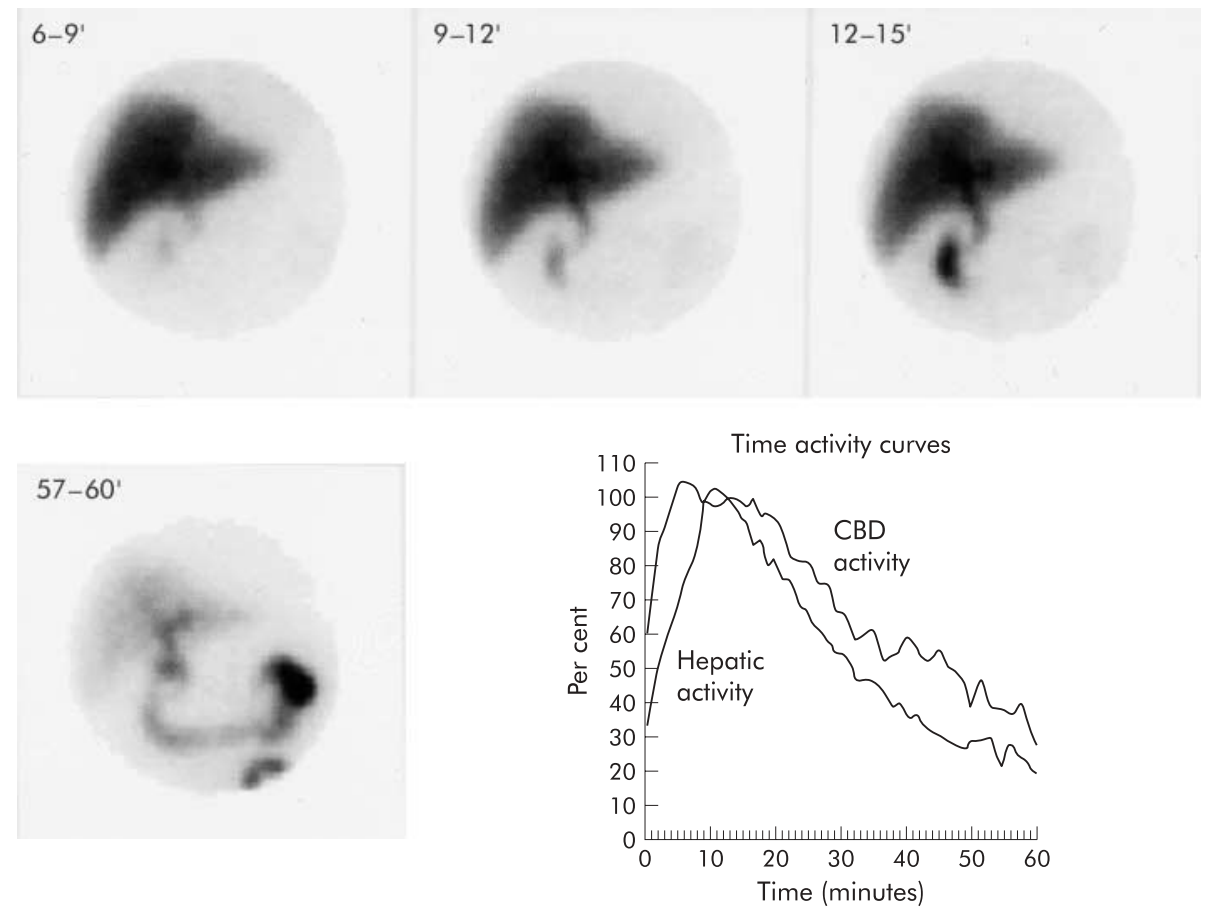

Figure 1 Four composite static images from the early phase of a scan and at its completion. Time since injection of diethyl iminodiacetic acid (DIDA) is indicated in the top left hand corner (in minutes). The time activity curves for liver and common bile duct (CBD) activity are also shown. This is a normal scan with a score of 1. Criteria for scoring are shown in table 1. In this patient peak hepatic activity was less than 10 minutes (see activity curve), the bile duct can be clearly seen in less than 15 minutes, the biliary tree is not prominent, the duodenum is clearly seen in less than 15 minutes, the CBD empties by more than $50 \%$ (see activity curve), and the CBD at 60 minutes, while more evident than the liver at the same time, is less active than the liver at 15 minutes (score 1). This patient had a normal sphincter of Oddi (SO) basal pressure of $23.2 \mathrm{~mm} \mathrm{Hg}$ at the time of SO manometry. These static images also show early appearance of duodenal activity (hepatic hilum to duodenal transit time four minutes, duodenal appearance time eight minutes).

then studied prospectively against SO manometry as the gold standard in patients with suspected SO dysfunction following cholecystectomy and found to have a sensitivity of $83 \%$ and $100 \%$ specificity when HDTT was longer than nine minutes in 19 patients studied..$^{15}$ However, a Finnish group has reported on a large group of 37 asymptomatic patients following cholecystectomy $^{16}$ and found mean HDTT to be 12 minutes. This is three minutes longer than the abnormal HDTT of nine minutes described by the Italian workers. ${ }^{15}$ In a recent small Danish study, ${ }^{17}$ HDTT was prolonged in patients with suspected SO dysfunction with an elevated basal pressure compared with patients with suspected SO dysfunction and a normal basal pressure. Furthermore, it was prolonged compared with asymptomatic post cholecystectomy control subjects. This group also reported prolonged appearance of nucleotide activity in the duodenum (duodenal appearance time (DAT)) in patients with SO dysfunction.

These studies demonstrate that uncertainty exists regarding which scintigraphic parameters can be applied with accuracy in the diagnosis of post cholecystectomy patients with suspected biliary SO dysfunction. Also, these scintigraphic approaches have only been subjected to limited evaluation. In a study which commenced in 1998, we undertook to prospectively assess the Sostre scoring system, HDTT, and DAT in post cholecystectomy patients with suspected biliary SO dysfunction, using SO manometry as the objective diagnostic standard of this condition.

\section{METHODS \\ Patients}

The study was approved by the Flinders Clinical Research Committee and patients with a past history of cholecystectomy, aged 18-80 years of age, with suspected biliary SO dysfunction, as defined by the Rome II criteria, ${ }^{1}$ were offered entry to the study from January 1998 to August 2000. The
Rome II criteria include the presence of at least one episode of biliary pain over the last 12 months in the absence of any structural abnormality in the biliary tree. Biliary pain was defined as intermittent episodes of severe pain well localised to the epigastrium or right upper quadrant. All patients had undergone endoscopic retrograde cholangiopancreatography (ERCP) within 12 months of study enrolment to rule out common bile duct stones. Female patients were excluded if pregnancy could not be ruled out.

Patients were also classified according to the clinical classification of Hogan and Geenen based on ERCP findings of a dilated common bile duct (CBD) greater than $12 \mathrm{~mm}$ and liver function test abnormalities. ${ }^{18}$

\section{Scintigraphy technique}

Patients underwent scintigraphy within one month prior to manometry, the majority within a week. Following a four hour fast, patients received an infusion of cholecystokinin octapeptide (CCK-OP) 20 ng/kg (Kinevac, Bracco Diagnostics, Mississauga, Ontario, Canada) over 45 minutes. Fifteen minutes after commencement of the CCK-OP infusion, $50 \mathrm{Mbq}$ 99mTc-diethyl iminodiacetic acid (DIDA) was injected intravenously. Digital images were obtained in the anterior projection, with the patient supine, at one frame per minute for 60 minutes using a Siemens orbiter/gamma camera and data stored on an Icon computer.

Regions of interest were placed over the right lobe of the liver (excluding visible bile ducts) and CBD to generate time activity curves. Three minute composite static images were recorded on film for subsequent visual assessment.

\section{Reporting of scintigraphy}

The Sostre score was assessed by two independent observers, as described by Sostre and colleagues. ${ }^{13}$ Both observers had no 

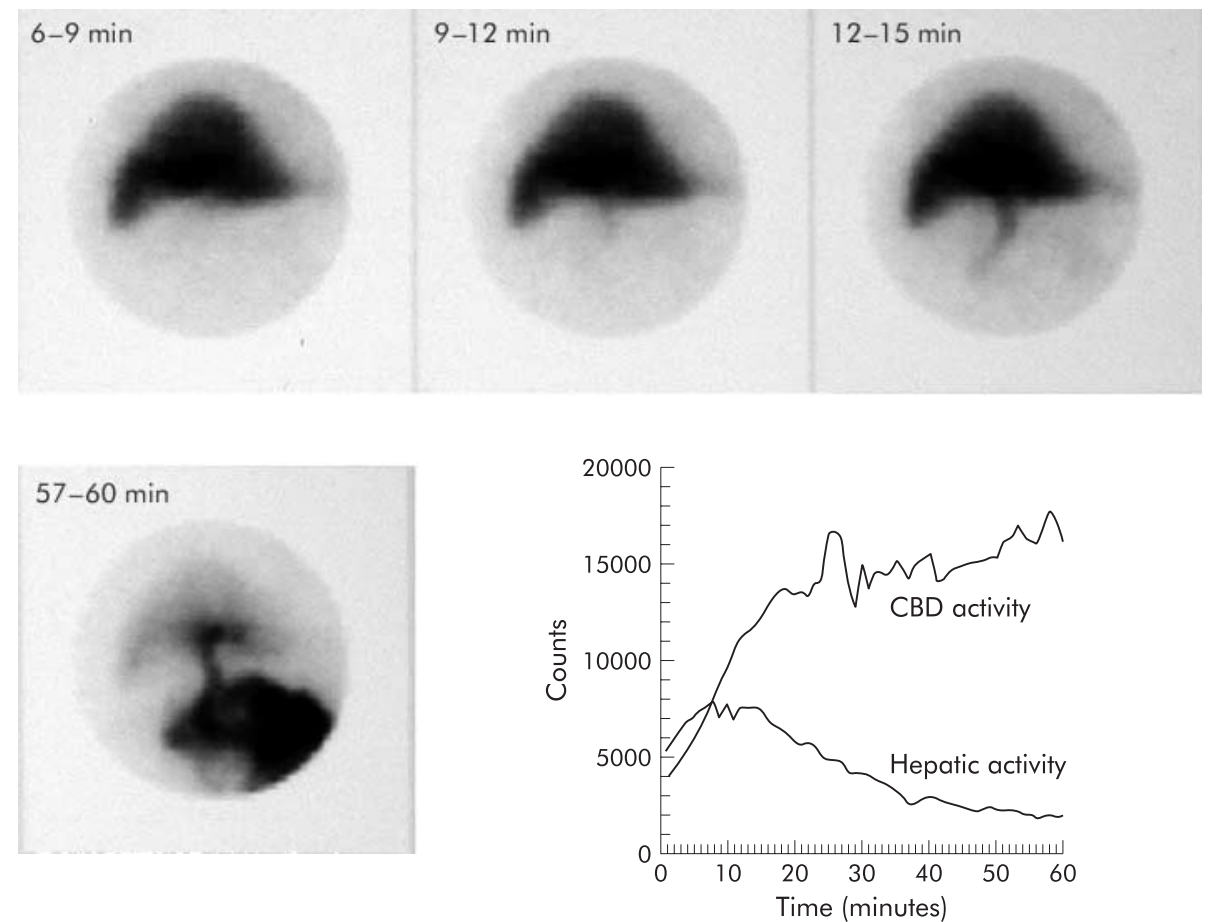

Figure 2 Static images from the same time points as well as time activity curves for a patient with sphincter of Oddi (SO) stenosis, as in fig 1. These static images, when compared with those in fig 1, show delayed appearance of tracer in the bile duct and duodenum, with the tracer at 60 minutes being more prominent in the biliary tree. This scan was scored by both observers as abnormal with a score of 6 . The duodenum was not clearly evident at 15 minutes (score 1) although when the scan was analysed to determine hepatic hilum to duodenal transit time (HDTT) and duodenal appearance time (DAT) by the third observer, DAT was found to be 14 minutes from the one minute digital images (HDTT eight minutes). There is increasing common bile duct (CBD) activity seen at 60 minutes from the time activity curve (score 3 ) and the CBD at 60 minutes is equal in intensity to the liver at 15 minutes (score 2). This patient had an elevated basal pressure of $94.2 \mathrm{~mm} \mathrm{Hg}$ and subsequently underwent sphincterotomy.

knowledge of the clinical scenario. This scoring system is outlined in table 1 and examples of a normal and abnormal studies are shown in figs 1 and 2. The six parameters include:

(1) Time of peak hepatic activity obtained from the liver time activity curve.

(2) Time at which the intrahepatic biliary tree was first visualised using the static images.

(3) Prominence or dilation of the biliary tree.

(4) Time at which the "bowel" was first visualised using static images. This was interpreted as when the duodenum or jejunum was clearly seen.

(5) Percentage of CBD emptying as determined from the time activity curve.

(6) CBD to liver ratio. This was determined by visually comparing $\mathrm{CBD}$ at 60 minutes with the liver parenchyma at 15 and 60 minutes from the static images.

The maximum score is 12 . Sostre defined a score of $\geqslant 6$ as abnormal and a score of $\leqslant 4$ as normal, with a score of 5 being regarded as an equivocal result.

Another independent observer determined HDTT and DAT from the one minute static digital images. Preliminary studies found no difference when determining these values between the static images and time activity curves determined from regions of interest at the hepatic hilum and duodenum with subtraction of hepatic activity.

\section{Manometry}

Patients underwent endoscopic SO manometry with a standard triple lumen catheter (Wilson-Cook, North Carolina, USA) with each lumen perfused at $0.13 \mathrm{ml} / \mathrm{min}$, as has been previously described. ${ }^{19}$ The assembly was withdrawn through the $\mathrm{SO}$ of the biliary duct. Patients in whom cannulation failed or was only possible from the pancreatic duct were excluded from data analysis. Manometry was assessed by two observers who were aware of the clinical scenario but were blinded as to the scintigraphy results. Basal pressure in the SO was taken as the mean of the lowest pressure points between SO pressure waves within a sustained high pressure zone seen in at least two of the three recording channels on two pull throughs. Duodenal pressure was used for the zero reference point; recordings were taken for at least two minutes. A basal pressure of greater than $40 \mathrm{~mm} \mathrm{Hg}$ was considered abnormal. $^{20}$

Manometric tracings were also assessed for evidence of SO dyskinesia ${ }^{20}$ which is seen manometrically as an incoordinate sphincter with several abnormalities described: rapid phasic wave frequency ( $>7$ phasic waves/min) often known as tachyoddia, excessive retrograde phasic wave propagation ( $>50 \%$ of phasic waves), high amplitude phasic waves ( $>300$ $\mathrm{mm} \mathrm{Hg}$ ), intermittent elevations of the sphincter basal pressure that relaxes with smooth muscle relaxants often termed "SO spasm", and a paradoxical response to CCK-OP administration (failure to inhibit phasic wave activity). An additional analysis was performed which included patients with SO dyskinesia as abnormal, but the main focus of the study defined abnormal as an elevated basal pressure.

\section{Statistics}

Sostre scores, HDTT, and DAT values were compared against manometry and the Hogan/Geenen classification using one way analysis of variance (ANOVA). Two by two tables were constructed to determine sensitivity, specificity, positive predictive values (PPV), and negative predictive values (NPV) for the Sostre scores, HDTT, and DAT, with various values being defined as abnormal, and with manometry as the gold standard. Interobserver variation for the scintigraphic score was 
Table 2 Mean Sostre score for both observers, hepatic hilum to duodenum transit time (HDTT), and duodenal appearance time (DAT) for abnormal and normal sphincter of Oddi (SO) basal pressure (SOBP)

\begin{tabular}{lll}
\hline & $\begin{array}{l}\text { SOBP }>40 \mathrm{~mm} \mathrm{Hg} \\
(\mathrm{n}=8)\end{array}$ & $\begin{array}{l}\text { SOBP }<40 \mathrm{~mm} \mathrm{Hg} \\
(\mathrm{n}=21)\end{array}$ \\
\hline Sostre score & $3.8(0.56)$ & $2.95(0.29)$ \\
HDTT (min) & $5.38(0.93)$ & $4.62(0.46)$ \\
DAT (min) & $10.63(1.11)$ & $10.0(0.72)$ \\
\hline
\end{tabular}

Values are mean (SEM)

assessed using the correlation coefficient. The correlation coefficient was also used to assess whether there was any relationship between basal pressure and scintigraphic variables.

\section{RESULTS}

Thirty two patients (30 females) agreed to enter the study. Mean age was 45.1 years (range $20-75$ ) with mean time since cholecystectomy 7.9 years (range 2 months to 32 years). Six of 32 patients had acalculous biliary disease. Mean time from cholecystectomy to the development of biliary pain was 4.9 years (range 0-22). Fifteen patients were classified as Hogan/ Geenen type II, with the remainder being type III. SO manometry from the bile duct was successfully performed in 29 of 32 patients. In two patients manometry could only be performed from the pancreatic duct and in one patient cannulation failed. These three patients were excluded from analysis. Eight of the remaining 29 patients had an elevated basal pressure (SO stenosis) and a further five patients had evidence of SO dyskinesia.

Mean Sostre scores, HDTT, and DAT were marginally higher in the group with an elevated basal pressure (table 2) but these differences were not statistically significant $(p=0.556$, 0.491, 0.779, respectively). For patients with an elevated basal pressure, sensitivity, specificity, PPV, and NPV for the Sostre score and HDTT are shown in tables 3 and 4. The results generally showed a low sensitivity and any adjustments in defini-
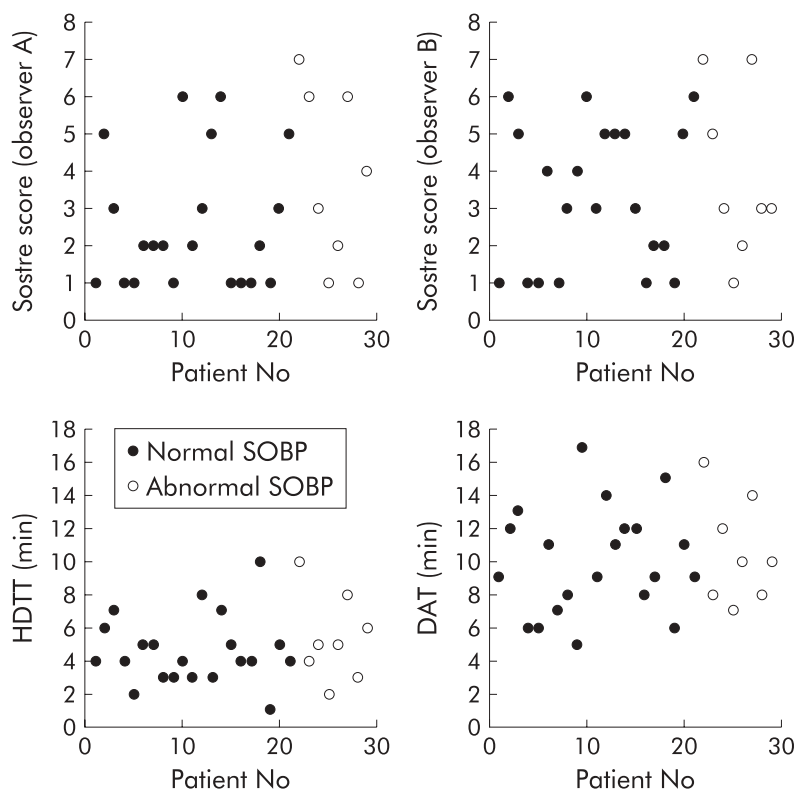

Figure 3 These four scatter graphs reveal the significant overlap between normal and abnormal manometry with respect to defining "cut off" values. SOBP, sphincter of Oddi basal pressure.

tions of abnormal for the scintigraphic measures to improve the sensitivity resulted in a worsening in specificity. Scatter plots of the Sostre score (observer A and B), HDTT, and DAT compared with normal and abnormal manometry are shown in fig 3 and demonstrate the significant overlap between patients with normal and abnormal manometry and the difficulty in choosing "cut off" values.

When the "cut off" values were applied for the Sostre score, as originally defined ${ }^{13}$ (that is, score $\geqslant 6$ abnormal, score $\leqslant 4$ normal, score 5 equivocal) the results for observer $\mathrm{A} / \mathrm{B}$, respectively, showed a sensitivity of $38 \% / 25 \%$ (PPV $60 \% / 40 \%$ ) and a specificity of $90 \% / 86 \%$ (NPV 79\%/75\%), with 3/6 patients having equivocal scores (only one patient with abnormal

Table 3 Sensitivity, specificity, positive predictive values (PPV), and negative predictive values (NPV) for Sostre scores for observer A and B, with a sphincter of Oddi basal pressure $>40 \mathrm{~mm} \mathrm{Hg}$ defined as abnormal

\begin{tabular}{lllll}
\hline & Sensitivity & Specificity & PPV & NPV \\
\hline Observer A & & & & \\
Score $\geqslant 6$ & $38 \%(10-74)$ & $90 \%(68-98)$ & $60 \%(17-93)$ & $79 \%(57-92)$ \\
Score $\geqslant 5$ & $38 \%(10-74)$ & $76 \%(52-91)$ & $38 \%(10-74)$ & $76 \%(52-91)$ \\
Score $\geqslant 4$ & $50 \%(17-83)$ & $76 \%(52-91)$ & $44 \%(15-77)$ & $80 \%(56-93)$ \\
Observer B & & & & $75 \%(53-89)$ \\
Score $\geqslant 6$ & $25 \%(4-64)$ & $86 \%(63-96)$ & $40 \%(7-83)$ & $72 \%(46-89)$ \\
Score $\geqslant 5$ & $38 \%(10-74)$ & $62 \%(39-81)$ & $27 \%(7-61)$ & $69 \%(41-88)$ \\
Score $\geqslant 4$ & $38 \%(10-74)$ & $52 \%(30-74)$ & $23 \%(6-54)$ & \\
\hline
\end{tabular}

Table 4 Sensitivity, specificity, positive predictive values (PPV), and negative predictive values (NPV) for hepatic hilum to duodenal transit time (HDTT in minutes), with a sphincter of Oddi basal pressure $>40 \mathrm{~mm} \mathrm{Hg}$ defined as abnormal

\begin{tabular}{lllll}
\hline & Sensitivity & Specificity & PPV & NPV \\
\hline HDTT $\geqslant 9$ & $13 \%(1-53)$ & $95 \%(74-100)$ & $50 \%(3-97)$ & $74 \%(53-88)$ \\
HDTT $\geqslant 8$ & $25 \%(4-64)$ & $90 \%(68-98)$ & $50 \%(9-91)$ & $76 \%(54-90)$ \\
HDTT $\geqslant 7$ & $25 \%(4-64)$ & $81 \%(57-94)$ & $33 \%(6-76)$ & $74 \%(51-89)$ \\
HDTT $\geqslant 6$ & $38 \%(10-74)$ & $76 \%(52-91)$ & $38 \%(10-74)$ & $76 \%(52-91)$ \\
HDTT $\geqslant 5$ & $63 \%(26-90)$ & $57 \%(34-77)$ & $36 \%(14-64)$ & $80 \%(51-95)$ \\
\hline
\end{tabular}

$95 \%$ confidence limits in parentheses. 
Table 5 Sensitivity, specificity, positive predictive values (PPV), and negative predictive values (NPV) for Sostre scores (defined as the highest value for both observers) and hepatic hilum to duodenal transit time (HDTT) times-results with sphincter of Oddi ( $\mathrm{SO}$ ) basal pressure $>40 \mathrm{~mm} \mathrm{Hg}$ and SO dyskinesia defined as abnormal

\begin{tabular}{lllll}
\hline & Sensitivity & Specificity & PPV & NPV \\
\hline Score $\geqslant 6$ & $31 \%(10-61)$ & $81 \%(54-95)$ & $57 \%(20-88)$ & $59 \%(37-79)$ \\
Score $\geqslant 5$ & $38 \%(15-68)$ & $63 \%(36-84)$ & $45 \%(18-75)$ & $56 \%(31-78)$ \\
Score $\geqslant 4$ & $46 \%(20-74)$ & $50 \%(26-74)$ & $43 \%(19-70)$ & $53 \%(27-78)$ \\
HDTT $\geqslant 9$ & $8 \%(0-38)$ & $94 \%(68-100)$ & $50 \%(3-97)$ & $56 \%(36-74)$ \\
HDTT $\geqslant 8$ & $15 \%(3-46)$ & $88 \%(60-98)$ & $50 \%(9-91)$ & $56 \%(35-75)$ \\
HDTT $\geqslant 7$ & $19 \%(5-46)$ & $81 \%(54-95)$ & $50 \%(14-86)$ & $50 \%(30-70)$ \\
HDTT $\geqslant 6$ & $38 \%(15-68)$ & $81 \%(54-95)$ & $63 \%(26-90)$ & $62 \%(39-81)$ \\
HDTT $\geqslant 5$ & $54 \%(26-80)$ & $56 \%(31-79)$ & $50 \%(24-76)$ & $60 \%(33-83)$ \\
\hline
\end{tabular}

$95 \%$ confidence limits in parentheses.

manometry). Although in 17 of 29 scans the observers of the Sostre score differed in their scores, the correlation coefficient $(r=0.722)$ showed that interobserver variability was not marked and mirrored the poor sensitivity/specificity results found from both observers.

The results for HDTT when a time of $\geqslant 9$ minutes was defined as abnormal, as previously defined by Corazziari and colleagues, ${ }^{15}$ showed a sensitivity of $13 \%$ (PPV 50\%) and a specificity of $95 \%$ (NPV 74\%). DAT results mirrored HDTT findings and are not shown. Inclusion of patients with SO manometric evidence of SO dyskinesia as abnormal did not improve the results for either the Sostre score (taken as the highest value from both observers) or the HDTT (table 5).

A dilated CBD may increase the capacitance of the biliary tree with alterations of the time activity curve for the CBD without the existence of a sphincter abnormality. When the six patients with a dilated CBD $\geqslant 12 \mathrm{~mm}$ were excluded from analysis, this improved Sostre score specificity to $100 \%$ but sensitivity remained poor at $17 \%$ with corresponding poor predictive values (PPV 50\%, NPV 71\%).

There was no correlation between SO basal pressure and HDTT or DAT $(r<0.01)$. Also, there was no association between the Hogan/Geenen classification with type II or III patients and the Sostre score and DAT ( $\mathrm{p}=0.126,0.782$, respectively). For HDTT, type II patients had a significantly longer time compared with type III patients $(5.1(0.6)$ minutes $v 3.0(0.4)$ minutes; $p=0.005$ ).

\section{DISCUSSION}

The potential for non-invasive evaluation of patients with suspected biliary SO dysfunction is attractive, especially with the advent of magnetic resonance cholangiopancreatography which can reliably image the biliary tree to exclude retained CBD stones, ${ }^{21}$ avoiding the need for ERCP. If scintigraphy were to prove a highly sensitive and specific test, it could be used as a screening test, with SO manometry being performed on patients in whom scintigraphic findings were equivocal. The findings of this study were that both the Sostre scoring system as well as HDTT and DAT showed poor sensitivity and specificity at our centre.

Our findings with respect to the Sostre score differed significantly from the initial report. ${ }^{13}$ Our study protocol was slightly different but this is unlikely to be a major factor in accounting for the divergent results. Sostre infused CCK-OP $20 \mathrm{ng} / \mathrm{kg}$ over three minutes, 15 minutes prior to injection of tracer, presumably in an attempt to stimulate bile flow and improve the yield of the test. Rapid infusion of CCK-OP has been shown to cause nausea as well as alter biliary dynamics $^{22}$ and its effect on SO may have dissipated prior to commencement of the actual study, as CCK-OP has been shown to inhibit SO phasic activity for only three minutes. ${ }^{23} \mathrm{~A}$ slower infusion is better tolerated and leads to a better physiological state, and for this reason we infused CCK-OP 20 $\mathrm{ng} / \mathrm{kg}$ over 45 minutes, starting 15 minutes prior to injection of the tracer. We used the tracer 99mTc-DIDA whereas Sostre used 99mTc-DISIDA. These differences are unlikely to have had any major effect on the scan.

Sostre's study can be criticised regarding the diagnosis of SO dysfunction. Two of 12 patients described as having SO dysfunction did not actually undergo manometry, but instead were diagnosed on clinical grounds. The 10 patients with manometric SO dysfunction included three patients with a normal SO basal pressure but a paradoxical response to CCKOP. Hence patients were a mixed group of SO stenosis (that is, elevated basal pressure) and dyskinesia. When patients with SO dyskinesia were included as "abnormal" in our analysis, no improvement in our results was evident. Another criticism of this scoring system is that it is quite subjective although significant interobserver variability was not observed in our study or in the original Sostre study. ${ }^{13}$

The Italian study that reported excellent results using HDTT also had potential weaknesses that may explain why our results differed. Seven of 19 patients had a normal basal SO pressure. However, two of these seven patients had a prolonged transit time. This would indicate poor specificity but in their analysis they included a control group of 11 asymptomatic subjects which may have improved the data. Our protocol differed from this Italian study in two ways. We used static images to determine HDTT by visually assessing when the tracer first reached the hepatic hilum and subsequently the duodenum, which as a technique has been reported by others as a way of assessing transit time. ${ }^{16}$ Our preliminary studies showed no differences between time activity curves or the use of static images to determine HDTT or DAT. The Italian group used a method which involved a subtraction technique to remove background tracer from the region of interest involving the right ventricle of the heart that requires 15 second scans. They believe that static images detect duodenal activity much later than using this subtraction technique. The Danish group that also described good results with HDTT used time activity curves but did not use the same subtraction technique that the Italians employed. The other difference between our protocol and the Italian study was that we infused CCK-OP to stimulate bile flow. The Danish group also infused CCK-OP.

The Finnish group that used visual assessment to determine HDTT reported on a large group of 37 asymptomatic patients following cholecystectomy (range one month to 30 years) ${ }^{16}$ The study found that mean transit time was 12 minutes (range 1-48; SD 11), which is clearly longer than the nine minutes the Italians used to differentiate normal from abnormal. This study also found that duration of time since cholecystectomy corelated with increasing HDTT, although this was not evident in our study (data not shown). 
While our biliary scintigraphy results were disappointing, this technique can hopefully be improved. The recent report of morphine stimulated biliary scintigraphy showing high rates of sensitivity and specificity compared with SO manometry using CBD tracer activity at 45 minutes $^{24}$ is promising. However, this approach needs to be confirmed by other groups before it is widely employed. Alternatives to scintigraphy in the non-invasive assessment of SO function may involve the development of "dynamic" MRCP and endoscopic ultrasound but neither of these techniques has been widely evaluated to date.

The use of biliary scintigraphy to evaluate flow through the SO as a measure of SO activity has enormous appeal. Compared with endoscopic manometry, it has the advantage of being non-invasive. In this study we have prospectively evaluated three scoring systems used to diagnose SO dysfunction and compared them with the accepted objective standard-that is, manometry-for diagnosing SO dysfunction. Our results show low concordance between the scintigraphic techniques and manometry and as such we cannot support their use for the diagnosis of SO dysfunction.

\section{ACKNOWLEDGEMENTS}

The National Health and Medical Research Council of Australia provided scholarship support to Dr Craig and project support (grant No 970001).

n...................

\section{Authors' affiliations}

A G Craig, G T P Saccone, J Toouli, Department of General and Digestive Surgery, Flinders University, South Australia, Australia D Peter, P Ziesing, A Wycherley, Department of Nuclear Medicine,

Flinders Medical Centre, South Australia, Australia

\section{REFERENCES}

1 Corazziari E, Shaffer EA, Hogan WJ, et al. Functional disorders of the biliary tract and pancreas. Gut 1999;45(suppl 2):1148-54.

2 Geenen JE, Hogan WJ, Dodds WJ, et al. Intraluminal pressure recording from the human sphincter of Oddi. Gastroenterology 1980;78:317-24

3 Toouli J, Roberts-Thomson IC, Kellow J, et al. Manometry based randomised trial of endoscopic sphincterotomy for sphincter of Oddi dysfunction. Gut 2000:46:98-102.

4 Scicchitano J, Saccone GTP, Baker RA, et al. How safe is endoscopic sphincter of Oddi manometry. J Gastroenterol Hepatol 1995; 10:334-6.

5 Maldonado ME, Brady PG, Mamel JJ, et al. Incidence of pancreatitis in patients undergoing sphincter of Oddi manometry (SOM). Am J Gastroenterol 1999:94:387-90.
6 Zeman RK, Burrell MI, Dobbins J, et al. Postcholecystectomy syndrome: evaluation using biliary scintigraphy and endoscopic retrograde cholangiopancreatography. Radiology 1985;156:787-92.

7 Shaffer EA, Hershfield NB, Logan K, et al. Cholescintigraphic detection of functional obstruction of the sphincter of Oddi. Effect of papillotomy. Gastroenterology 1986;90:728-33.

8 Grimon G, Buffet C, Andre L, et al. Biliary pain in postcholecystectomy patients without biliary obstruction. A prospective radionuclide study. Dig Dis Sci 1991:36:317-20.

9 Fullarton GM, Allan A, Hilditch T, et al. Quantitative $99 \mathrm{mTc}-\mathrm{DISIDA}$ scanning and endoscopic biliary manometry in sphincter of Oddi dysfunction. Gut 1988;29:1397-401

10 Farup PG, Tjora S. Sphincter of Oddi dysfunction. Dynamic cholescintigraphy and endoscopic retrograde cholangiopancreatography with papillotomy in diagnosis, treatment, and follow-up study. Scan J Gastroenterol 1989;24:956-60.

11 Darweesh RM, Dodds WJ, Hogan WJ, et al. Efficacy of quantitative hepatobiliary scintigraphy and fatty-meal sonography for evaluating patients with suspected partial common duct obstruction. Gastroenterology 1988;94:779-86.

12 Roberts-Thomson IC, Toouli J, Blanchett W, et al. Assessment of bile flow by radioscintigraphy in patients with biliary-type pain after cholecystectomy. Aust N Z J Med 1986;16:788-93.

13 Sostre S, Kalloo AN, Spiegler EJ, et al. A noninvasive test of sphincter of Oddi dysfunction in postcholecystectomy patients: the scintigraphic score. J Nucl Med 1992;33:1216-22.

14 Cicala M, Scopinaro F, Corazziari E, et al. Quantitative cholescintigraphy in the assessment of choledochoduodenal bile flow. Gastroenterology 1991;100:1106-13.

15 Corazziari E, Cicala M, Habib Fl, et al. Hepatoduodenal bile transit in cholecystectomized subjects. Relationship with sphincter of Oddi function and diagnostic value. Dig Dis Sci 1994;39:1985-93.

16 Sand JA, Turianmaa VM, Koskinen MO, et al. Variables affecting quantitative biliary scintigraphy in asymptomatic cholecystectomized volunteers. Hepatogastroenterology 1999;46:130-5.

17 Madacsy L, Middelfart HV, Matzen P, et al. Quantitative hepatobiliary scintigraphy and endoscopic sphincter of Oddi manometry in patients with suspected sphincter of Oddi dysfunction: assessment of flow-pressure relationship in the biliary tract. Eur J Gastroenterol Hepatol 2000:12:777-86.

18 Hogan WJ, Geenen JE. Biliary dyskinesia. Endoscopy 1988;1:179-83.

19 Toouli J, Craig A. Sphincter of oddi function and dysfunction. Can J Gastroenterol 2000;14:411-19.

20 Toouli J, Roberts-Thomson IC, Dent J, et al. Manometric disorders in patients with suspected sphincter of Oddi dysfunction. Gastroenterology 1985:88: 1243-50

21 Barish MA, Yucel EK, Ferrucci JT. Magnetic resonance cholangiopancreatography. N Engl J Med 1999;341:258-64.

22 Ziessman HA, Fahey FH, Hixson DJ. Calculation of a gallbladder ejection fraction: advantage of continuous sincalide infusion over the three-minute infusion method. J Nucl Med 1992;33:537-41.

23 Toouli J, Hogan WJ, Geenen JE, et al. Action of cholecystokinin-octapeptide on sphincter of Oddi basal pressure and phasic wave activity in humans. Surgery 1982;92:497-503.

24 Thomas PD, Turner JG, Dobbs BR, et al. Use of $(99 \mathrm{~m})$ Tc-DISIDA biliary scanning with morphine provocation for the detection of elevated sphincter of oddi basal pressure. Gut 2000;46:838-41. 